\section{THE ARREST OF HÆMORRHAGE DURING AMPUTATION AT THE HIP-JOINT.}

\section{To the Editor of THE LANCET.}

SIR, - The question of the best method of arresting hæmorrhage during amputation at the bip-joint has been recently discussed at the Clinical Society and in your columns. I should like to be allowed to draw attention to an application of Esmarch's elastic tourniquet-not, as far as I can discover, mentioned in his "Surgeon's Handbook," though it has probably been often employed before-which I found, in amputating at the hip in a boy fourteen years of age, answer its purpose perfectly, without causing the slightest inconvenience to the operator.

The limb was first elevated in order to render it bloodless, and when this result had been obtained the pelvis was raised from the table, and the india-rubber band was placed loosely in the perineum, after slipping it through two loops of bandage, one in front and one behind, which were drawn across to the opposite side of the body and held firmly above the iliac crest by an assistant. The two ends of the india-rubber band were then drawn rapidly and tightly outwards, were crossed below the iliac crest of the side on which the amputation was to be performed, and were then made to encircle the pelvis once, passing on the opposite side between the iliac crest and the great trochanter. The arrangement of the loops of bandage and of the india-rubber band will be gathered from the accompanying sketch.

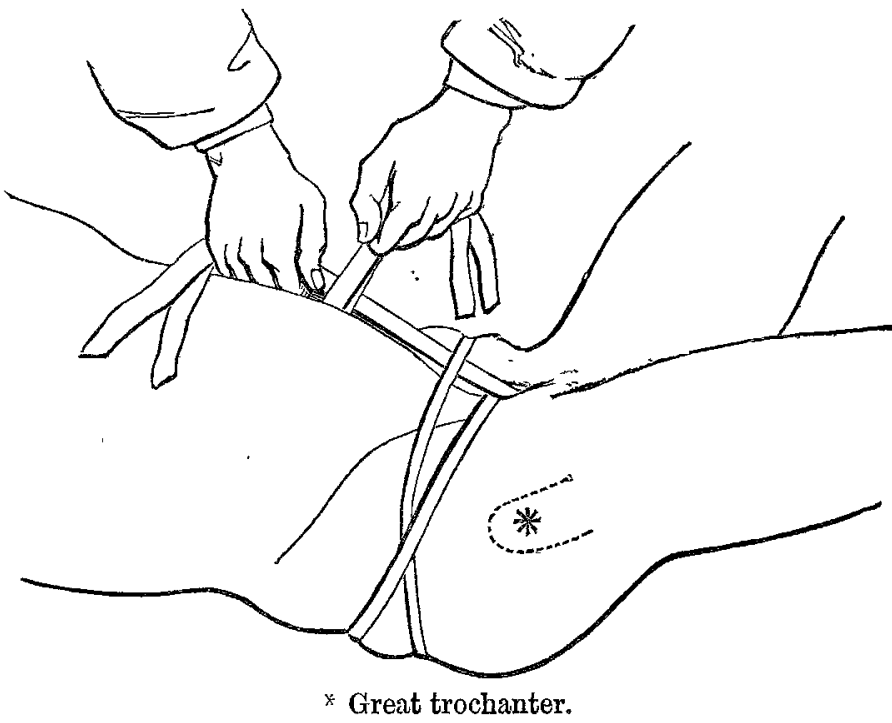

This method has the advantage of compressing the vessels in the posterior flap as well as the commencement of the common femoral, and it enabled me to perform the oval amputation quite bloodlessiy, and as slowly as was desired. As the band does not pass round the waist, no fear need be entertained of its interfering with respiration. It remains to be seen whether it is equally applicable to the large thigh of a muscular adult as to the small one of a boy of fourteen. I am, Sir, yours truly,

RICKMAN J. GODLEE,

Henrietta-street, Cavendish-square, June, 1880.

\section{"THE LANCET" COMMISSION ON WORKHOUSE INFTRMARIES.}

To the Editor of THE LANCET.

StR,-In reference to your introductory remarks in your issue of the 22nd ult., in favour of an entire separation of the sick poor from the pauper class, $I$ beg to offer the following remarks in support of your proposition, based on an experience of over twenty years as one of the guardians of the Cork workhouse, which contains at present a population of 2683 persons.

The great object that we all ought to have in view is the prompt and efficient relief of the destitute and the sick poor at the lowest possible cost consistent with the efficient treatment of them.

The massing-up of human beings composed of all the varied classes in workhouses, such as the convicted and unconvicted criminal, the drunkard and vicious of both sexes, together with the well-conducted destitute poor persons, is a sad mistake ; the system tends to perpetuate crime and all its sad accompaniments, while an increasing poor-rate declares in unmistakable language the evil results of our poor-law system.

Separation of those classes appears to me to be the only remedy. Why should the honest, well-conducted poor mar: or woman, who seeks hospital relief, be placed in a ward with the rogue and vagabond? Why should the former, when recovering, be compelled to sleep in a bed with the latter? Why should the innocent child over three years of age, when sent in for hospital treatment to a workhouse, be placed in the adult wards of the hospital? Is it not proved by experience that evil associations are the ruin of our people. Yet in all the Irish workhouses will be found no separate wards for the well-conducted and the badly-conducted classes, notwithstanding that the workhouse regulations appear to provide for the separation of the children from the adults; and although they have separate wards to live in when they are in health, strange to say when they become sick they are placed in the hospitals with the adults. Imagine for a moment a young lad associat ing in a sick-room with a pickpocket or a thief. Here lies the root of one of our sources of criminals, and it is no wonder that our workhouses under these circumstances should supply the ranks of the criminal classes.

Let a beginning be made, such as you suggest, in the way of separate hospitals, removed altogether from workhouses, where the working man or his wife or children can receive medical treatment without the danger of the evil associa. tions of a workhouse; and when they are recovered and fit to leave the hospital, let them not be permitted to remain, as they are in workhouses. "Once in a workhouse always in a workhouse" is becoming a proverb, and although the annual mortality in the Cork workhouse is upwards of 600 , the numbers in the house are steadily increasing, and they will continue to do so until a separate hospital is provided, or the healthy persons kept in some other institution.

Cork, June 6th, 1880 . Wir, yours \&., D'EsterRe PARKer.

\section{ON THE EXCISION OF OBSTRUCTION AT THE NECK OF THE BLADDER. \\ To the Editor of THE LANCET.}

STR,-Mr. Teevan's reply furnishes a complete warran for my calling in question his statement, that there are " hundreds of men now alive to whom Mercier has restored the faculty of free and natural micturition." He quotes Mercier's own statement as follows:- "Car mes opérations s'élèvent au moins au nombre de trois cents ;" but it will scarcely perhaps be believed that this is only half the sentence; the other half, omitted by Mr. Teevan, being "certains de mes malades ayant été opérés plusieurs fois," proving that Mercier himself is desirous to explain the large and incredible number of his cases by saying that on several he has operated many times. The other writers named by Mr. Teevan speak not on their own authority, but only on that of Mercier, like Mr. Teevan, not having done the operation themselves. Mr. Gonley, whom he cites in his favour, particularly speaking of the operation with disapproval. ${ }^{1}$

What now becomes of the number of patients? And still more important, what becomes of the value of the operation itself, which must be so often repeated? As to these cases of Mercier's, all performed more than thirty years ago, it would be curious to speculate on the ages of the old gentlemen supposed still to be perambulating Paris. The fact is, as I originally stated, a few cases were done by Mercier only or chiefly many years ago; the proceeding has long since fallen through as useless and dangerous, and no surgeon of eminence in Paris ever does it.

I must omit, as irrelevant to the present subject, the consideration of the side-issue started by Mr. Teevan, of the removal of prostatic tumours, whether accidentally or purposely, in the operation of lithotomy or by the special device of cystotomy. What I undertook to impugn was Mr. Teevan's advocacy of Mercier's operation of incising and excising prostatic obstructions by means of instruments passed down the urethra.-I am, Sir, yours, \&c.,

Wimpole-street, June 25th, 1880 . G. BUCKSTON BROWNE. 